\title{
Two strains of nonstarter lactobacilli increased the production of flavor compounds in soft cheeses
}

\author{
M. M. Milesi, I. V. Wolf, C. V. Bergamini, and E. R. Hynes ${ }^{1}$ \\ Instituto de Lactología Industrial, Universidad Nacional del Litoral - Consejo Nacional de Investigaciones Científicas y Técnicas, \\ $1^{\circ}$ de mayo 3250, S3000AOM, Santa Fe, Argentina
}

\begin{abstract}
The contribution to flavor generation and secondary proteolysis of 2 strains of mesophilic lactobacilli isolated from cheese was studied. Miniature soft cheeses $(200 \mathrm{~g})$ were produced with or without the inclusion of a culture of Lactobacillus plantarum I91 or Lactobacillus casei $\mathrm{I} 90$ in the starter composed of Streptococcus thermophilus. During ripening, cheeses containing the added lactobacilli showed an increased content of total free amino acids, but this increase was only significant in cheeses with $L b$. plantarum I91. In addition, free amino acid profiles were modified by selective increases of some amino acids, such as Asp, Ser, Arg, Leu, and Phe. Cheeses inoculated with $L b$. plantarum I91 or $L b$. casei 190 were also characterized by a significantly higher concentration of diacetyl, a key flavor compound, and an increased content of acetoin. Results suggest an increase in the catabolism of either citrate or aspartate, with the production of the derived aroma compounds. Overall, aspartate content increased in both lactobacilli-added cheeses, whereas citrate was more or less constant, suggesting that aspartate could be the source of increased diacetyl and acetoin. A triangle aroma test showed that the addition of the lactobacilli strains significantly changed the sensory attributes of cheeses. At least 11 of 12 panelists commented that the aroma of cheeses with adjuncts was more buttery than that of control cheeses, which is desirable in most soft cheeses. Both Lb. plantarum I91 and Lb. casei 190 performed well as adjunct cultures by influencing cheese aroma development and cheese proteolysis.
\end{abstract}

Key words: nonstarter lactobacilli, flavor compound, soft cheese

\section{INTRODUCTION}

In recent decades, several strategies aimed at reducing the number of adventitious microorganisms in cheesemilk were successfully implemented. Enhance-

Received December 30, 2009.

Accepted July 25, 2010.

${ }^{1}$ Corresponding author: ehynes@fiqus.unl.edu.ar ment of hygienic standards in dairy farms and innovation in thermal (pasteurization) and nonthermal (microfiltration, bactofugation) sanitization treatments have allowed milk of excellent microbiological quality to be obtained. These technologies increase the safety of dairy products, but also lead to a dramatic reduction of the autochthonous microflora, particularly nonstarter lactic acid bacteria (NSLAB), that impart diverse and typical characteristics to cheeses. Today, consumers demand cheeses of consistent quality, without defects, but also with the more intense flavors that were typical of these products in previous decades and seem to have disappeared in modern cheeses (Grappin and Beuvier, 1997; Crow et al., 2001; Hynes and Bergamini, 2006).

To deal with two conflicting requirements; that is, the need for NSLAB required for the development of a mature flavor and the need to prevent defects caused by uncontrolled and potentially detrimental NSLAB, the most accepted approach consists of including adjunct cultures of mesophilic lactobacilli in cheesemaking (Crow et al., 2001; Wouters et al., 2002). Adjunct cultures of mesophilic lactobacilli are selected strains of NSLAB that are added to cheesemilk with a purpose other than acidification (Wouters et al., 2002). Their principal objective is the control of adventitious microflora to obtain products of satisfactory and uniform quality (Martley and Crow, 1993; Williams et al., 2002). Adjunct cultures may inhibit adventitious NSLAB either directly, by production of inhibiting substances such as lactic acid or bacteriocins, or indirectly, through competition for the limited pool of substrates and growth factors occurring in the cheese (Martley and Crow, 1993; Peláez and Requena, 2005). In addition to being used as control agents, adjunct cultures of mesophilic lactobacilli with interesting metabolic attributes may be used to accelerate cheese ripening or to contribute to the production of volatile compounds with more intense and distinctive flavor notes (Macedo et al., 2000; Tavaria et al., 2002; Wouters et al., 2002; Tavaria and Malcata, 2003; Banks and Williams, 2004).

The main role of secondary proteolysis in cheese flavor is to provide the precursors for aroma development; that is, free amino acids. A direct contribution of proteolysis to cheese taste is also possible through for- 
mation and breakdown of bitter peptides from caseins (McSweeney and Sousa, 2000).

Catabolism of amino acids is the main metabolic route for the formation of flavor compounds in most cheese varieties, and in lactic acid bacteria this transformation is initiated by a transamination step (McSweeney and Sousa, 2000; Smit et al., 2005; Yvon, 2006). Transamination is catalyzed by aminotransferases, which transform an amino acid into its corresponding $\alpha$-ketoacid in the presence of an acceptor of amino group, generally $\alpha$-ketoglutarate. To date, specific aminotransferases for degradation of aspartic acid, aromatic amino acids, and branched-chain amino acids have been isolated from lactic acid bacteria; some of these enzymes are also active on methionine (Tanous et al., 2002; Yvon, 2006). After transamination, $\alpha$-ketoacids, which are the most important intermediates in the production of flavor compounds, may be hydrogenated to $\alpha$-hydroxyacids, decarboxylated to aldehydes, or converted to acetyl-CoA esters. The latter can be metabolized into carboxylic acids. Moreover, aldehydes may be further transformed to alcohols by reduction or to carboxylic acids by oxidation. All these compounds, except hydroxyacids, are important contributors to cheese flavor (Tanous et al., 2002; Smit et al., 2005).

Metabolism of lactose and citrate is also important to cheese flavor; lactic acid bacteria can produce small quantities of ethanol, acetic acid, and other molecules characteristic of cheese flavor from lactose. As for citrate metabolism, citrate-positive lactic acid bacteria are key agents for production of diacetyl and acetoin, which impart the main sensory characteristics to butter and soft cheeses (McSweeney and Sousa, 2000; Yvon, 2006). Recently, the production of diacetyl and acetoin has been linked to aspartate catabolism by lactic acid bacteria strains with Asp-aminotransferase activity, both in a reaction medium containing $\alpha$ - ketoglutarate (Le Bars and Yvon, 2008) and in model cheeses when cultures also showed glutamate dehydrogenase (GDH) activity (Kieronczyk et al., 2004).

The present study investigated the contribution of 2 strains of mesophilic lactobacilli isolated from cheese, Lactobacillus plantarum I91 and Lactobacillus casei I90, to secondary proteolysis, production of volatile compounds and organic acids, and aroma of soft cheeses. For this purpose, the strains were assayed as adjunct cultures in miniature Cremoso cheeses made under controlled microbiological conditions.

\section{MATERIALS AND METHODS}

\section{Adjunct Cultures}

Lactobacillus plantarum I91 and Lb. casei I90 were isolated in the Instituto de Lactología Industrial (INLAIN,
Universidad Nacional del Litoral, CONICET, Santa Fe, Argentina) from a good quality, 2-mo-old Tybo cheese. The strains were previously characterized by in vitro assays; they showed suitable technological properties, resistance to biological barriers, and potential as probiotic organisms, which made them good candidates for adjunct cultures in cheesemaking (Bude-Ugarte et al., 2006; Briggiler-Marcó et al., 2007).

Strains were cultivated twice in de Man, Rogosa, and Sharpe (MRS) broth (Britania, Buenos Aires, Argentina) at $34^{\circ} \mathrm{C}$ overnight, from stock cultures (stored at $-80^{\circ} \mathrm{C}$ in MRS broth with $15 \%$ glycerol). An aliquot of the overnight cultures, enough to attain a concentration of $10^{6} \mathrm{cfu} / \mathrm{mL}$ in the cheesemilk, was centrifuged for $20 \mathrm{~min}$ at $8,000 \times g$ and $4^{\circ} \mathrm{C}$. The pellet was washed twice with $0.1 M$ sodium phosphate buffer $(\mathrm{pH} 7)$ and then resuspended in the same buffer before adding it to the cheesemilk.

\section{Cheesemaking}

Lactobacillus plantarum I91 and Lb. casei I90 were assayed as single adjunct cultures in miniature Cremoso cheeses, an Argentinean soft-cheese variety, in 2 cheesemaking trials: trial 1 ( $L b$. plantarum I91) and trial 2 (Lb. casei I90). In each trial, 2 types of cheeses were manufactured: control cheeses containing Streptococcus thermophilus as primary starter, and experimental cheeses with the same primary starter and the adjunct culture. Control cheeses were labeled $\mathrm{C} 1$ and $\mathrm{C} 2$ for trials 1 and 2, respectively. Experimental cheeses from trial 1, containing $L b$. plantarum I91 as adjunct culture, were named E1, and those from trial 2, containing $L b$. casei I90, were named E2. The number of cheeses (experimental units) in each trial was 8 (4 control cheeses and 4 experimental cheeses), and a total of 16 cheeses of about $200 \mathrm{~g}$ each were produced during the entire project. Duplicates were obtained on different cheesemaking days with different pasteurized milks. Cheesemaking, as well as cheese surface drying, packing, and sampling were performed under controlled microbiological conditions (Milesi et al., 2007). Samples (approximately 20 g) were taken at the molding step (time 0) and after 3 d. After that, cheeses were vacuum-packed and ripened at $5^{\circ} \mathrm{C}$. At d 30, cheeses were unpacked, sampled, and vacuum-packed again in new sterile plastic bags. At 60 $\mathrm{d}$, a new sample was taken and the rest of the cheese was used for the triangle aroma test.

\section{Gross Composition, $\mathrm{pH}$, and Microbial Counts of Cheeses}

Gross composition and $\mathrm{pH}$ of cheeses were assessed at $3 \mathrm{~d}$ of ripening by standard methods. Moisture was 
determined by oven drying $\left(102 \pm 1^{\circ} \mathrm{C}\right.$; IDF, 1982), fat matter by a butyrometric method (IDF, 1997), and protein content by the Kjeldahl method (IDF, 1993). pH was recorded according to American Public Health Association standard (Bradley et al., 1993).

Starter populations were determined on skim milk agar after incubation at $37^{\circ} \mathrm{C}$ for $48 \mathrm{~h}$ (Frank et al., 1993). Adventitious and adjunct lactobacilli in control and experimental cheeses, respectively, were enumerated by counting samples on MRS agar (Britania) after incubation at $34^{\circ} \mathrm{C}$ for $48 \mathrm{~h}$ under microaerophilic conditions (Bude-Ugarte et al., 2006). Coliforms were counted on bile red violet agar after $24 \mathrm{~h}$ at $32^{\circ} \mathrm{C}$ (Christen et al., 1993), whereas molds and yeasts were enumerated on yeast extract-dextrose (glucose)-chloramphenicol agar after $5 \mathrm{~d}$ of incubation at $25^{\circ} \mathrm{C}$ (Frank et al., 1993).

\section{Free Amino Acids Analysis by Reverse Phase-HPLC}

Quantification of free AA (FAA) was performed by reverse phase-HPLC in water-soluble fractions of 3- and 60 -d-old cheeses. A precolumn derivatization method using 6-aminoquinolyl- $N$-hydroxi-succinimidyl carbamate followed by HPLC was used for the determination of FAA in cheese samples. For that, the chemistry package of the Waters AccQ-Tag Amino Analysis Method (Waters Corp., Milford, MA) was used, which comprises the reagent kit for the derivatization reaction, the column, a mixture of amino acid standard, sample tubes, and the eluents. The HPLC equipment consisted of a quaternary pump, an on-line degasser, and UV/ visible detector, all Series 200 (Perkin Elmer, Norwalk, CT). An interface module connected to a computer was used for acquisition of chromatographic data with the software Turbochrom (Perkin Elmer). A 3.9- × 150-mm Nova-Pak $\mathrm{C}_{18}, 4-\mu \mathrm{m}$ column (Waters Corp.) specifically certified for use with the AccQ.Tag Method and a 15$\times 3.2-\mathrm{mm}, 7-\mu \mathrm{m}$ guard column (Perkin Elmer) were used. Sample preparation, derivatization reaction, and chromatographic separation were performed according to Bergamini et al. (2009).

\section{Analysis of Organic Acids and Acetoin by HPLC}

Organic acids were analyzed by HPLC, using the same equipment as that used for FAA analysis, described previously. Chromatographic separation was performed isocratically at $65^{\circ} \mathrm{C}$ with a mobile phase of $10 \mathrm{mM} \mathrm{H} \mathrm{H}_{2} \mathrm{SO}_{4}$ at a flow rate of $0.6 \mathrm{~mL} / \mathrm{min}$ on a Bio-Rad Aminex HPX-87H column $(300 \times 7.8 \mathrm{~mm}$, Bio-Rad, Hercules, CA). Water-soluble extracts of the cheeses at 3 and $60 \mathrm{~d}$ were obtained by blending $5 \mathrm{~g}$ of cheese and $15 \mathrm{~mL}$ of distilled water with mortar and pestle, warming the mixture to $40^{\circ} \mathrm{C}$, and maintain- ing at that temperature for $1 \mathrm{~h}$. The suspension was centrifuged at $3,000 \times g$ for $30 \mathrm{~min}$ and filtered through fast-flow filter paper. The filtered solution was adjusted to a final volume of $25 \mathrm{~mL}$. Samples were filtered again, this time through $0.45-\mu \mathrm{m}$ membranes (Millex, Millipore, São Paulo, Brazil), and $60 \mu \mathrm{L}$ was injected into the HPLC chromatograph. Detection was performed at $210 \mathrm{~nm}$ for the following acids: citric, pyruvic, succinic, lactic, and acetic. Acetoin and propionic acid, whose peaks partially overlapped, were quantified by performing detection at both wavelengths taking into account that acetoin absorbs at 210 and $285 \mathrm{~nm}$ and propionic acid only at $210 \mathrm{~nm}$ (Zeppa et al., 2001). Analyticalgrade organic acids (Sigma Aldrich, St. Louis, MO) were used as standards to obtain calibration curves.

\section{Volatile Compounds by Headspace-Solid-Phase Microextraction-GC Analysis}

Volatile compounds were assessed at 3 and $60 \mathrm{~d}$ of ripening in the headspace of cheese samples $(5 \mathrm{~g})$, which were placed in $30-\mathrm{mL}$ glass vials, hermetically sealed, and equilibrated at $40 \pm 1^{\circ} \mathrm{C}$ for $10 \mathrm{~min}$. A $1 \mathrm{~cm} \times$ $50 / 30 \mu \mathrm{m}$ Stable-Flex divinylbenzene/carboxen/polydimethylsiloxane (DVB/CAR/PDMS) fiber (Supelco, Bellefonte, PA) was exposed in the headspace for 30 min. During sampling, the vials were maintained at 40 $\pm 1^{\circ} \mathrm{C}$. Volatile compounds adsorbed on the fiber were immediately thermally desorbed in the injector of the chromatograph.

A gas chromatograph equipped with a PE-Wax column (polyethylene glycol, $60 \mathrm{~m}, 0.25$-mm i.d, 0.25$\mu \mathrm{m}$ film thickness; Perkin Elmer) and coupled to an ion trap mass spectrometer (GC-MS Shimadzu QP5000, Shimadzu, Tokyo, Japan) was used to identify compounds. Conditions were as follows: ionization by electron impact at $70 \mathrm{eV}$; source temperature, $260^{\circ} \mathrm{C}$; acquisition range 42 to $300 \mathrm{~m} / z$; and scan rate 250 $\mathrm{amu} / \mathrm{s}$. Thermal desorption was performed in splitless mode at $250^{\circ} \mathrm{C}$ for $5 \mathrm{~min}$. Carrier gas was helium (flow rate of $3 \mathrm{~mL} / \mathrm{min}$ ). Oven temperature was maintained at $45^{\circ} \mathrm{C}$ for $4 \mathrm{~min}$, increased to $150^{\circ} \mathrm{C}$ at $5^{\circ} \mathrm{C} / \mathrm{min}$ and maintained $3 \mathrm{~min}$, and then increased to $250^{\circ} \mathrm{C}$ at $8^{\circ} \mathrm{C} /$ min and held for $5 \mathrm{~min}$. Compounds were identified by matching mass spectra with the NIST-62 library (mass spectral database of the National Institute of Standards and Technology) and with the spectra of injected standards as well as on the retention times of the standards, where available.

Flame-ionization detection was used to obtain information of peak areas (expressed in arbitrary units) and to compare the profiles of the different cheeses. The analyses were conducted under the same chromatographic conditions as used for GC-MS. 
Table 1. Counts of microbial groups $\left(\log _{10} \mathrm{cfu} / \mathrm{g}\right)$ during ripening of miniature control and experimental Cremoso cheeses from trials 1 and $2^{1}$

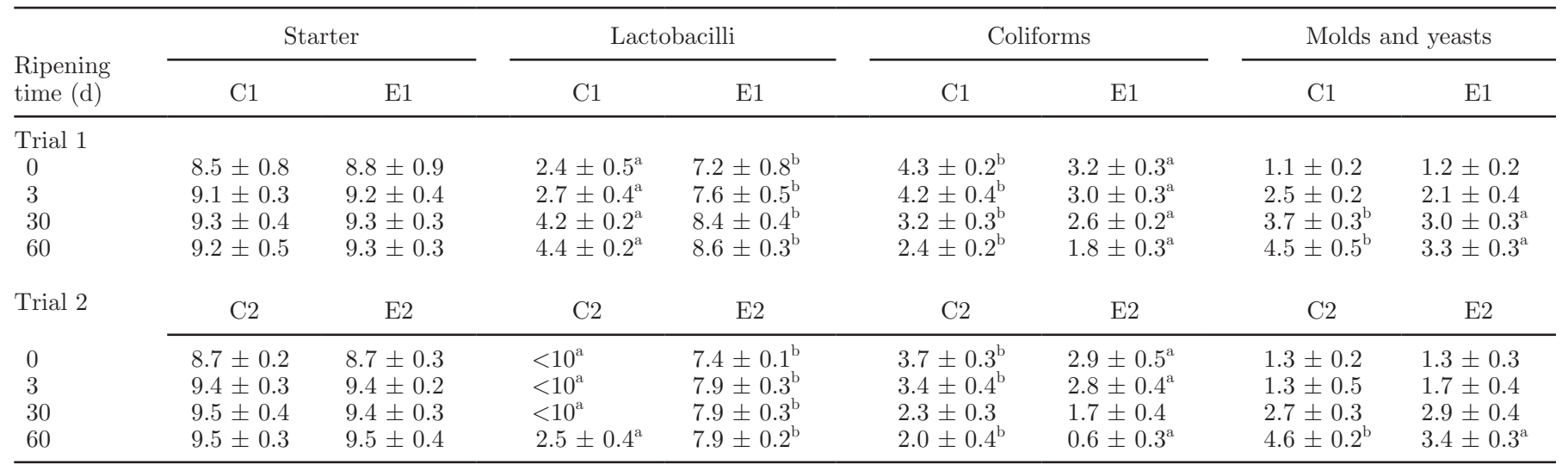

${ }^{\mathrm{a}, \mathrm{b}}$ Means in the same row and within the same microbial group with different superscript differ $(P \leq 0.05)$.

${ }^{1} \mathrm{C} 1$ and $\mathrm{C} 2=$ control cheeses from trials 1 and 2, respectively; E1 and E2 = experimental cheeses inoculated with Lactobacillus plantarum I91 (trial 1) and Lactobacillus casei I90 (trial 2), respectively.

\section{Sensory Analysis}

The contribution of $L b$. plantarum I91 and $L b$. casei I90 to aroma development of soft cheeses was assessed at the end of the ripening period $(60 \mathrm{~d})$ by comparing the aroma of cheeses made with or without adjunct cultures by a triangle aroma test (AFNOR, 1995) as described by Milesi et al. (2007). Samples ( $5 \mathrm{~g}$ ) were placed in sealed glass containers and maintained in an oven at $30^{\circ} \mathrm{C}$ for $30 \mathrm{~min}$, after which they were provided to the panel. The same containers were re-equilibrated in the oven and reused twice. Three samples were supplied to each panelist; 2 of the samples had been taken from the same cheese, whereas the third was different. The samples were identified with random 3-digit codes. The panel, composed of 12 untrained members, was asked to find the sample that differed and to comment briefly on the differences. The panelists evaluated cheese duplicates but they did not replicate measurements with the same cheeses.

\section{Statistical Analysis}

Data from chemical composition, microbiological counts, FAA, and organic acid and volatile compound assays were analyzed by one-way ANOVA with a $95 \%$ confidence level. All analyses were made in duplicate. All statistical analyses were performed using the SPSS 10.0 software (SPSS Inc., Chicago, IL).

\section{RESULTS AND DISCUSSION}

\section{Chemical Composition and Microbial Counts}

No significant differences were found $(P>0.05)$ in $\mathrm{pH}$, moisture, fat matter, and protein content between 3-d-old miniature Cremoso cheeses made with or without lactobacilli cultures. In both experiments, these parameters ranged from 5.17 to 5.29 , from 50.54 to 52.09 (\% wt/wt), from 23.60 to 25.67 (\% wt/wt), and from 19.23 to 20.13 (\% wt/wt), respectively. Moreover, all values were similar to those reported by Milesi et al. (2007) for miniature Cremoso cheeses and were within the normal ranges expected for commercial Cremoso cheeses.

Counts of streptococci and lactobacilli in cheeses from both trials are shown in Table 1. Streptococcus thermophilus reached numbers of $10^{9} \mathrm{cfu} / \mathrm{g}$ after manufacture, which remained constant during ripening. This result was verified for all cheeses, with or without the addition of $L b$. plantarum I91 or Lb. casei 90, which suggests that the tested strains did not interfere with Strep. thermophilus growth and survival.

Lactobacilli cultures were added into cheesemilk at a concentration of $10^{6} \mathrm{cfu} / \mathrm{mL}$ and reached counts of $10^{7} \mathrm{cfu} / \mathrm{g}$ in the curd (d 0$)$, principally due to bacterial concentration during cheesemaking. After $3 \mathrm{~d}$, lactobacilli counts increased by $\sim 1 \log$ cycle $\left(10^{8} \mathrm{cfu} / \mathrm{g}\right)$ and then remained constant toward the end of ripening. This trend confirmed the findings of previous studies on Lb. plantarum I91 and Lb. casei I90, which showed that both strains are able to grow and maintain high cell densities in cheeses and cheese models, even when coupled with different primary starters and under diverse dairy environments (Briggiler-Marcó et al., 2007; Milesi et al., 2007, 2008). Many strains of lactobacilli isolated from cheese and reinoculated as adjunct cultures during subsequent cheese manufacture can remain viable in cheese (McSweeney et al., 1994; Poveda et al., 2003); however, not all strains are able to increase their concentrations in this food matrix (Hynes et al., 2003b; 
Table 2. Total amount of free AA (calculated as the sum of the individual contents of all free AA assessed; $\mathrm{mg} / 100 \mathrm{~g}$ of cheese) during ripening of miniature control and experimental Cremoso cheeses from trials 1 and 2

\begin{tabular}{lcc}
\hline & \multicolumn{2}{c}{ Ripening time $(\mathrm{d})$} \\
\cline { 2 - 3 } Cheese $^{1}$ & 3 & 60 \\
\hline Trial 1 & & \\
C1 & $41.2 \pm 17.2$ & $46.5 \pm 8.1^{\mathrm{a}}$ \\
E1 & $40.6 \pm 17.8$ & $88.9 \pm 9.3^{\mathrm{b}}$ \\
Trial 2 & $35.6 \pm 2.9$ & $39.3 \pm 4.5$ \\
C2 & $41.2 \pm 5.7$ & $55.8 \pm 5.9$ \\
E2 & & \\
\hline
\end{tabular}

${ }^{\mathrm{a}, \mathrm{b}}$ Means in the same column and within the same trial with different superscript differ $(P \leq 0.05)$.

${ }^{1} \mathrm{C} 1$ and $\mathrm{C} 2=$ control cheeses from trials 1 and 2, respectively; E1 and $\mathrm{E} 2$ = experimental cheeses inoculated with Lactobacillus plantarum I91 (trial 1) and Lactobacillus casei I90 (trial 2), respectively.

Morea et al., 2007). Comparative studies in different dairy matrices are scarce (Milesi et al., 2008).

In control cheeses in both trials, adventitious lactobacilli were undetectable or counts remained very low $\left(10^{2}\right.$ to $\left.10^{4} \mathrm{cfu} / \mathrm{g}\right)$, which is a prerequisite for identification of biochemical changes attributable to the studied adjunct cultures (Hynes et al., 2003a,b). In our cheese model, the difference in lactobacilli counts between lactobacilli-treated cheeses and their respective controls was always $>4 \log$ units.

Coliform counts were, on average, $10^{4}$ and $10^{3} \mathrm{cfu} / \mathrm{g}$ in the curd $(0 \mathrm{~d})$ of control and experimental cheeses, respectively, but then decreased by 2 log cycles toward $60 \mathrm{~d}$ of ripening. In contrast, initial counts of molds and yeasts in all cheeses were negligible $\left(\sim 10^{1} \mathrm{cfu} / \mathrm{g}\right)$, but then increased gradually, reaching approximately $10^{4}$ and $10^{3} \mathrm{cfu} / \mathrm{g}$ after $60 \mathrm{~d}$ in control and experimental cheeses, respectively. The significantly lower levels of nonlactic contaminants in lactobacilli-added cheeses suggest that $L b$. plantarum I91 and $L b$. casei $\mathrm{I} 90$ could have a negative effect on the growth of undesirable microflora. Similar results regarding lower coliform growth in adjunct-treated cheeses were recently observed for other strains of nonstarter lactobacilli, which were generally explained as being a consequence of bacteriocins or increased acid production (Ortigosa et al., 2006; Mangia et al., 2008).

\section{Levels of FAA}

In trial 1, total content of FAA (calculated as the sum of the individual contents of all the FAA assessed) in cheeses with $L b$. plantarum I91 was significantly higher than in control cheeses at the end of ripening $(P$ $\leq 0.05$ ). Also in trial 2 , cheeses with $L b$. casei I90 had higher amount of total FAA than their controls at $60 \mathrm{~d}$ of ripening, but this increase was not significant $(P>$ 0.05 ; Table 2).

The individual FAA profiles of miniature Cremoso cheeses from trials 1 and 2 are shown in Figure 1A and $1 \mathrm{~B}$, respectively. Patterns were similar to those previously reported for Cremoso cheese: Leu, Phe, Lys, and Arg were the most abundant amino acids in the miniature cheeses manufactured in the present work, whereas levels of Leu, Arg, Ala, and $\gamma$-aminobutyric acid (GABA) were the highest in traditional Cremoso cheeses according to Hynes et al. (1999). The latter were analyzed by a method that, unlike the technique used in this paper, did not detect Phe and was capable of quantifying GABA (Hynes et al., 1999).

Control and experimental cheeses showed similar levels of FAA at the beginning of ripening $(3 \mathrm{~d})$, but significant differences $(P \leq 0.05)$ were detected after 60 d. In fact, the levels of some FAA (Ser, His, Arg, Asp, Thr, Pro, Tyr, Leu, and Phe) were significantly $(P \leq 0.05)$ higher in cheeses with $L b$. plantarum $\mathrm{I} 91$ compared with their respective control cheeses. Similar results were obtained in trial 2 : cheeses with $L b$. casei I90 showed significantly $(P \leq 0.05)$ higher concentrations of some FAA (Asp, Ser, Arg, Leu, and Phe) than control cheeses.

The obtained results showed that $L b$. plantarum I91 had the strongest effect on the levels of FAA, which suggests a higher peptidolytic activity of this strain compared with $L b$. casei I90. Our results are in agreement with those of Farkye et al. (1995), who found that the proteolytic capability of a $L b$. casei strain was lower than that of 2 strains of Lb. plantarum, but this feature is strain-dependent (Parra et al., 1996; Oneca et al., 2007).

\section{Organic Acids and Acetoin}

The levels of each compound in control and experimental cheeses for trials 1 and 2 are shown in the Table 3 . The concentrations of each quantified organic acid varied greatly between cheese replicates, which is not surprising because these molecules are intermediate compounds in several metabolic pathways active in cheese during ripening (Buffa et al., 2004).

Lactic acid is the main product of fermentation of lactose by lactic acid bacteria and was the most abundant organic acid in all cheeses, as expected (Buffa et al., 2004). Citrate is mostly lost in whey during cheesemaking, but was the second most abundant organic acid in all samples. In other cheese types, such as Halloumi, citrate was not detected (Kaminarides et al., 2007), whereas in Cheddar cheese, as in this case, it was reported to be the second most abundant acid after lactate (Izco et al., 2002). 
A)

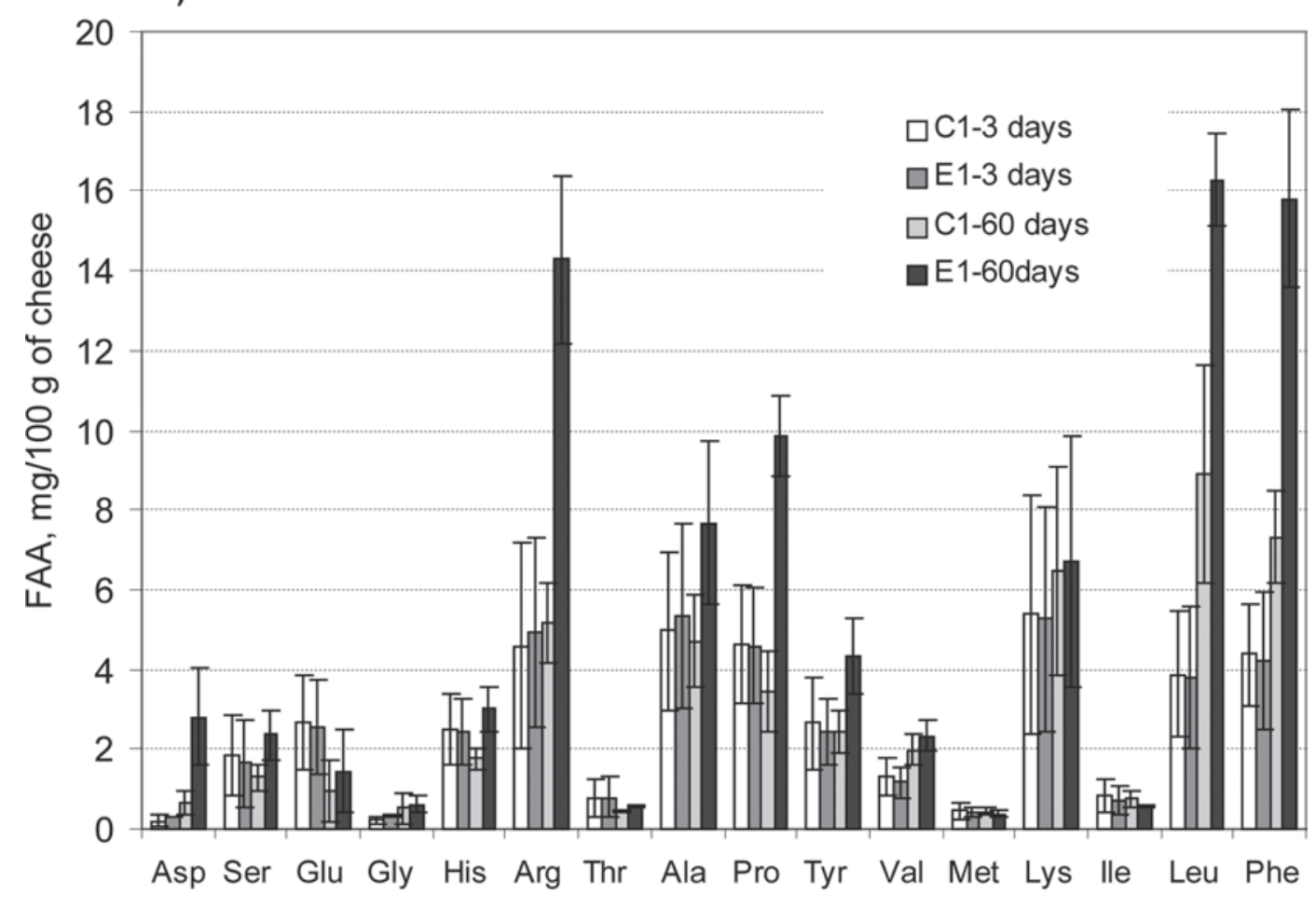

B)

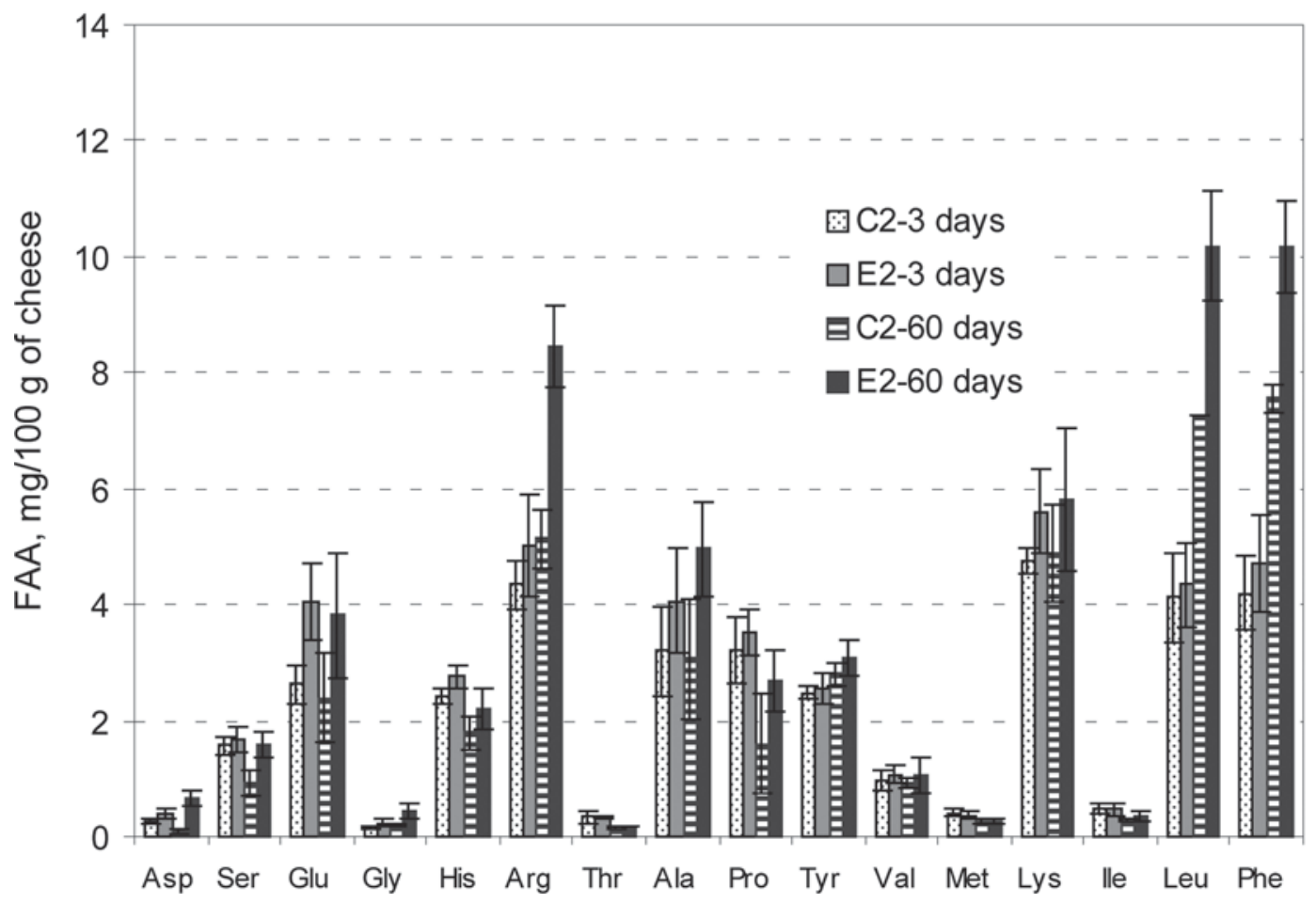

Figure 1. Individual free amino acid (FAA) profiles of 3- and 60-d-old miniature control and experimental Cremoso cheeses from trial 1 (A) and 2 (B). C1 and C2 = control cheeses from trials 1 and 2, respectively; E1 and E2 = experimental cheeses inoculated with Lactobacillus plantarum I91 (trial 1) and Lactobacillus casei I90 (trial 2), respectively. 
Lactobacillus plantarum I91 showed a greater acidifying activity than $L b$. casei I90, because lactic acid increased during ripening and was significantly different between control and lactobacilli-added cheeses after $60 \mathrm{~d}$. This result suggests that $L b$. plantarum I91 may cause postacidification in the product; however, the changes in lactic acid were not correlated with changes in cheese $\mathrm{pH}$. Cheeses with Lb. casei I90 had similar content of lactic acid as control cheeses, both at the beginning and the end of ripening.

Cheeses with $L b$. plantarum I91 and Lb. casei I90 had significantly higher amounts of acetoin compared with control cheeses $(P \leq 0.05)$. Acetic acid content did not differ between control and lactobacilli-added cheeses, although it was always somewhat lower in the latter. Succinic acid was only found in cheese samples of trial 1 at $3 \mathrm{~d}$ of ripening; its source is probably the milk used in this particular cheesemaking. Lues (2000) noted that initial composition of cheesemilk introduces variation in organic acid contents in cheese. Pyruvic acid is an important intermediate in many pathways, such as metabolism of lactose, citrate, and free amino acids (Kaminarides et al., 2007). Its content was similar in control and experimental cheeses in both trials, as was that of citric and propionic acids.

Acetoin and diacetyl have been reported as typical flavor compounds of soft and fresh cheese varieties, characterized by a buttery note (McSweeney and Sousa, 2000). Diacetyl threshold values found in the literature range between 1 and $550 \mu \mathrm{g} / \mathrm{kg}$, depending on the food matrix and method of assessment, with the lowest values being reported for cheese (Preininger and Grosch, 1994; Le Quéré and Molimard, 2003; Smit et al., 2005). An acetoin threshold value is not available in the literature (Le Quéré and Molimard, 2003) but its odor has been described as being 100-fold less powerful than that of diacetyl (Le Bars and Yvon, 2008). Consequently, it can be reasonably expected that levels of acetoin $>50$ $\mathrm{mg} / \mathrm{kg}$ would contribute to cheese aroma. In the present work, acetoin content in cheeses at the beginning and the end of ripening were, on average, $>200 \mathrm{mg} /$ $\mathrm{kg}$, and the 60-d-old experimental cheeses had significantly higher amounts of acetoin than control cheeses. Diacetyl was not detected by HPLC, because this compound might have been lost during sample preparation (cheese extraction with water). Similarly, Palles et al. (1998) detected acetoin, but not diacetyl, by a similar HPLC methodology in in vitro assays used to study the metabolism of citrate by Lactobacillus spp.; these authors attributed this result to the small amounts of diacetyl produced by lactobacilli.

Acetoin, as well as diacetyl, can be produced by the catabolism of citrate or aspartate by certain strains of mesophilic lactobacilli, as was observed in in vitro as-

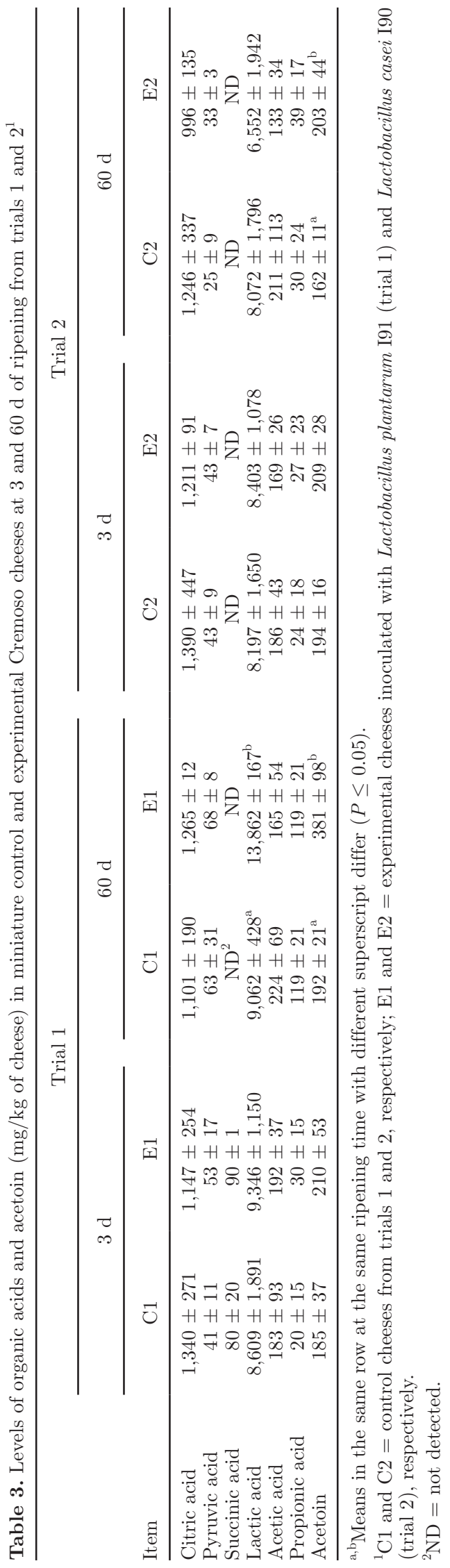


says (Kieronczyk et al., 2004; Díaz-Muñiz et al., 2006; Skeie et al., 2008a), in cheese slurry (Kieronczyk et al., 2004; Díaz-Muñiz et al., 2006), and in cheeses (Thage et al., 2005; Skeie et al., 2008a,b). In this study, the citrate level was similar in control and experimental cheeses of both trials, whereas aspartate concentration was always higher in experimental cheeses. These results suggest that the higher level of acetoin in experimental cheeses could derive from catabolism of aspartic acid by the added lactobacilli cultures. However, the Aspaminotransferase activity in these strains should be verified by in vitro assays to add more evidence to this hypothesis. Yvon (2006) observed that this pathway for generation of diacetyl is the most common one in ripened cheeses because diacetyl formation from citrate generally occurs at a very early stage during cheese ripening, alongside growth of lactic acid bacteria. Kocaoglu-Vurma et al. (2008) did not find a correlation between levels of citrate and diacetyl in Swiss cheeses with the addition of adjunct lactobacilli, which was attributed to the fact that the mechanisms by which diacetyl is formed in cheese are not completely understood.

\section{Volatile Compounds}

Volatile compounds found in control and experimental cheeses at 3 and $60 \mathrm{~d}$ of ripening are shown in Table 4 and included ketones, alcohols, acids, esters, and some aldehydes. In general, the same compounds were found in both types of cheeses, but some quantitative differences were detected (Table 4).

Ethanol was the most abundant volatile compound extracted, under the conditions of this study, from the headspace of all cheeses. Ethanol is a common volatile compound of cheese; it has been frequently found in other types of cheeses (Kondyli et al., 2002). No previous report on typical Cremoso cheese volatile compounds is available to date.

In both trials, levels of diacetyl at 3 and $60 \mathrm{~d}$ of ripening and acetoin at $60 \mathrm{~d}$ of ripening were significantly higher in experimental cheeses than in control cheeses. At the end of the ripening, the levels of these flavor compounds were on average 6-fold higher in cheeses with $L b$. plantarum 191 and 3 -fold higher in cheeses with $L b$. casei I90, compared with their control cheeses. The levels of acetoin increased in experimental cheeses during ripening, but decreased in control cheeses. Diacetyl concentration decreased in both types of cheeses with age, but this decrease was more pronounced in control cheeses. Others researchers (Bintsis and Robinson, 2004; Skeie et al., 2008a) have observed a marked decrease in the concentration of diacetyl and acetoin with ripening time, which is not surprising if an initial concentration of these volatile compounds is available in the young cheese and then lost through the rind, and no further production of diacetyl is possible (Yvon, 2006). However, if diacetyl and acetoin could be produced during ripening from the potentially available substrates, replenishment of this compound would be achieved in the cheese. The obtained results suggest that both lactobacilli strains assayed in the present work were able to produce acetoin and diacetyl in experimental cheeses. However, the fact that acetoin increased and diacetyl decreased during ripening might indicate that acetoin is more easily formed in cheese than diacetyl, because production of the latter requires $\mathrm{O}_{2}$, which is limited in the cheese environment (McSweeney and Sousa, 2000; Skeie et al., 2008b).

In addition to the differences described previously, concentrations of ethyl hexanoate and ethyl octanoate were significantly higher in the controls than in the experimental cheeses in both trials. Ethyl esters of the straight-chain fatty acids of $\mathrm{C} 2$ to $\mathrm{C} 10$ are potent flavor compounds at $<5 \mathrm{mg} / \mathrm{kg}$ (Liu et al., 2003; Abeijón Mukdsi et al., 2009). They are frequently found in cheeses and play an important role in the typical aroma of grana-type cheeses (Qian and Reineccius, 2003) and other cheese varieties (Liu et al., 2004), to which they give characteristic fruity notes. In other cheeses, such as Cheddar, fruity aroma is considered an off-flavor (McSweeney and Sousa, 2000). Esters can be produced by lactic and nonlactic microflora; among the latter, yeasts are strong producers of esters (Curioni and Bosset, 2002). The ability to form ethyl esters has been investigated in an extensive number of lactic acid bacteria strains of dairy origin, revealing large species and strain differences (Liu et al., 1998, 2003). However, Strep. thermophilus strains have, on average, significantly higher ethyl ester-synthesizing activity than other lactic acid bacteria (Liu et al., 2003). In the present work, the higher levels of esters in control cheeses were coincident with the presence of the primary starter of Strep. thermophilus alone, without added lactobacilli. We have observed a similar trend in ewe cheeses manufactured with Strep. thermophilus or with Strep. thermophilus plus lactobacilli (Bergamini et al., 2010). Control cheeses also had higher counts of yeasts and molds than experimental cheeses.

The levels of methyl acetate, hexanone, and decanoic acid were significantly higher in experimental cheeses with $L b$. plantarum I91 in trial 1 . Control cheeses from this trial had significantly higher amounts of 2-pentanol, 1-heptanol, propanone, and phenylethyl alcohol. Particularly, increased levels of phenylethyl alcohol are indicative of aromatic amino acid catabolism and are 
Table 4. Volatile compounds (peak area in arbitrary units) in miniature control and experimental Cremoso cheeses at 3 and $60 \mathrm{~d}$ of ripening from trials 1 and $2^{1}$

\begin{tabular}{|c|c|c|c|c|c|c|c|}
\hline \multicolumn{4}{|c|}{ Trial 1} & \multicolumn{4}{|c|}{ Trial 2} \\
\hline \multicolumn{2}{|c|}{$3 \mathrm{~d}$} & \multicolumn{2}{|c|}{$60 \mathrm{~d}$} & \multicolumn{2}{|c|}{$3 \mathrm{~d}$} & \multicolumn{2}{|c|}{$60 \mathrm{~d}$} \\
\hline $\mathrm{C} 1$ & E1 & $\mathrm{C} 1$ & E1 & $\mathrm{C} 2$ & $\mathrm{E} 2$ & $\mathrm{C} 2$ & E2 \\
\hline
\end{tabular}

Volatile compound

\section{$52 \pm 1$}

$55+5$

2-Butanone

Diacetyl

2-Hexanone

2-Heptanone

Acetoin

2-Nonanone

Alcohols

2-Propanol

Ethanol

2-Butanol

2-Pentanol

1-Butanol

3-Methyl 1-butano

1-Pentanol

2-Heptanol

1-Hexanol

1-Heptanol

Phenylethyl alcohol

Esters

Methyl acetate

Ethyl acetate

Ethyl butanoate

Ethyl hexanoate

Ethyl octanoate

Aldehydes

Acetaldehyde

Benzaldehyde

Acids

Acetic acid

Butanoic acid

3-Methyl butanoic acid

Hexanoic acid

Octanoic acid

$45+7$

$55 \pm 5$

$140 \pm 31^{\mathrm{a}}$

$52 \pm 12$

$115 \pm 5^{\mathrm{a}}$

$422 \pm 152$

$147 \pm 17$

$76 \pm 4$

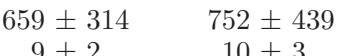

$9 \pm 2$

$\pm$

$\mathrm{ND}^{2}$

$8,849 \pm 364$

ND

$27+9 \quad 8,475 \pm 41$

$\begin{array}{ll}27 \pm 9 & 29 \pm 5 \\ 23 \pm 3 & 27 \pm 9\end{array}$

ND

ND

$43 \pm 27$

$11 \pm 5$

$8 \pm 2$

$7 \pm 3$

ND

ND
$41 \pm 24$

$12 \pm 7$

$12 \pm 5$

$8 \pm 3$

$26 \pm 10$

$189 \pm 4$

$2,813 \pm 762$

$500 \pm 257$

$24 \pm 5$

$206 \pm 25$

$2,347 \pm 307$

$337 \pm 65$

$105 \pm 26 \quad 79 \pm 22$

$\begin{array}{rlrl}7 & \pm 1 & 7 & \pm 2 \\ 81 & \pm 9^{\mathrm{b}} & 41 & \pm 20^{\mathrm{a}}\end{array}$

$119 \pm 7$

$244 \pm 28$

$33 \pm 15$

$256 \pm 44$

$182 \pm 56$

$23 \pm 7$

$125 \pm 11$

$276 \pm 72$

$26 \pm 12$

$193 \pm 82$

$133 \pm 31$

$32 \pm 17$

$31 \pm 3^{\mathrm{b}}$
$21 \pm 7$
$46 \pm 8^{\mathrm{a}}$
$21 \pm 5^{\mathrm{a}}$
$65 \pm 12$
$146 \pm 40^{\mathrm{a}}$
$31 \pm 25$

$18 \pm 4^{\mathrm{a}}$

$136 \pm 46^{\mathrm{a}}$

$45 \pm 8^{\mathrm{a}}$

$28 \pm 7$

$287 \pm 67^{\mathrm{b}}$

$40 \pm 7^{\mathrm{b}}$

$\begin{aligned} 66 & \pm 0.4 \\ 036 & \pm 406^{\mathrm{b}}\end{aligned}$

$12 \pm 1$

$3,271 \pm 406$

$51 \pm 38^{\circ}$

$149 \pm 21^{\mathrm{a}}$
$1,107 \pm 86$

$8 \pm 3$

ND

$12,338 \pm 1,693$

ND

$45 \pm 3$

$40 \pm 3^{\mathrm{b}}$

$6 \pm 2$
$172 \pm 97$

$25 \pm 5$

$22 \pm 7$

$13 \pm 2$

$80 \pm 4^{\mathrm{b}}$

$476 \pm 333^{\mathrm{a}}$

$13,305 \pm 957$

$11 \pm 5^{\mathrm{a}}$

$5,224 \pm 997^{\mathrm{b}}$

$19 \pm 1$

$48 \pm 33$

$20 \pm 8^{\mathrm{a}}$

$76 \pm 19$
$36 \pm 19$

$20 \pm 8$

$7 \pm 2$

$21 \pm 6$

$8 \pm 3^{\mathrm{a}}$

$15 \pm 4^{\mathrm{a}}$

$302 \pm 103$

$\begin{aligned} 3,250 & \pm 1,189\end{aligned}$

$4,549 \pm 769^{\mathrm{b}}$

$1,005 \pm 293^{\mathrm{b}}$

$20 \pm 4^{\mathrm{b}}$

$53 \pm 21^{\mathrm{b}}$

$554 \pm 189$

$5,637 \pm 311$

$1,865 \pm 48^{\mathrm{a}}$

$6 \pm 1$
$209 \pm 67$

$392 \pm 139^{\mathrm{a}}$

$7 \pm 1$

$248 \pm 28$

$758 \pm 106$

$20 \pm 5$

$388 \pm 47$

$98 \pm 44$
$23 \pm 8^{\mathrm{a}}$

$465 \pm 151$

$806 \pm 71$

$21 \pm 11$
$510 \pm 103$

$120 \pm 35$

$120 \pm 35$
$46 \pm 10^{\mathrm{b}}$

\section{b Different supersc}

$23 \pm 8$

$25+2$

$46 \pm 8^{\mathrm{a}}$

$27 \pm 10^{\mathrm{a}}$

$77 \pm 20$

ND

$20 \pm 6$

ND
ND

$364 \pm 16^{\mathrm{b}}$

$63 \pm 3^{\mathrm{b}}$

$4,962 \pm 199^{\mathrm{b}}$

$502 \pm 61^{\mathrm{b}}$

$1,077 \pm 158$

$10 \pm 1$

$38 \pm 2^{\mathrm{b}}$

$1,912 \pm 423^{\mathrm{a}}$

$18 \pm 3$

$53 \pm 25$

$168 \pm 12^{\mathrm{b}}$

$60 \pm 15^{\mathrm{b}}$
$71 \pm 24$

ND

$44 \pm 7^{\mathrm{a}}$
$13 \pm 5$

ND

$74 \pm 26^{\mathrm{b}}$

$566 \pm 109$

$58 \pm 16^{\mathrm{b}}$

$15 \pm 4^{\mathrm{b}}$

$8 \pm 1^{\mathrm{a}}$

$24 \pm 5^{\mathrm{b}}$

$128 \pm 50$

$227 \pm 36$

$44 \pm 15^{\mathrm{b}}$

$173 \pm 19$

$104 \pm 52$
$29 \pm 6$

ND

ND

$28 \pm 4^{\mathrm{a}}$

$500 \pm 11$

$24 \pm 4^{\mathrm{a}}$
$7 \pm 2^{\mathrm{a}}$

$62 \pm 8$

$134 \pm 27^{\mathrm{a}}$

$16 \pm 5$

$210 \pm 119$

$556 \pm 212^{\mathrm{a}}$

$43 \pm 28$

$137 \pm 3$

$58 \pm 4$

$532 \pm 54$

$84 \pm 11$

$1,602 \pm 202^{\mathrm{b}}$

$15 \pm 6$

$26 \pm 6$

$5,537 \pm 481$

$17 \pm 4$

$18 \pm 2^{\mathrm{a}}$

$8 \pm 4$
$26 \pm 12^{\mathrm{a}}$

$82 \pm 43$

$20 \pm 9$

$41 \pm 13$

$12 \pm 2$

$55 \pm 40$

$10 \pm 1$

$117 \pm 15^{\mathrm{a}}$

$3,702 \pm 1,808$

$715 \pm 163^{\mathrm{b}}$
$113 \pm 32^{\mathrm{b}}$

$23 \pm 20$
$777 \pm 946$

$4,777 \pm 946$

$19 \pm 5$

$6 \pm 0.8$

$160 \pm 38^{\mathrm{b}}$

$126 \pm 13$

$9 \pm 0.3$

$9 \pm 0.5$

$9+3$

$204 \pm 26^{\mathrm{b}}$

$1,767 \pm 1,116$

$18 \pm 2^{\mathrm{a}}$

$$
8 \pm 2
$$

$9 \pm 2$

$\mathrm{ND}^{\mathrm{a}}$

ND

$158 \pm 60$

$317 \pm 94$

$17 \pm 6^{\mathrm{a}}$

$199 \pm 48$

$157 \pm 78$
$42 \pm 14$

$179 \pm 16^{\mathrm{a}}$

$817 \pm 117$

$26 \pm 3^{\mathrm{b}}$

$295 \pm 12$

$69 \pm 7$
$22 \pm 5$

superscripts indicate significant differences $(P<0.05)$ in the same row, within the same trial, and for the same ripening time.

${ }^{\mathrm{C}} 1$ and $\mathrm{C} 2=$ control cheeses from trials 1 and 2, respectively; E1 and E2 = experimental cheeses inoculated with Lactobacillus plantarum I91 (trial 1 ) and Lactobacillus casei I90 (trial 2), respectively

${ }^{2} \mathrm{ND}=$ not detected 
associated with rose flower notes. Phenylethyl alcohol has a perception threshold in a cheese base of $9.1 \mathrm{mg} /$ kg (Molimard and Spinnler, 1996).

In trial 2, cheeses with $L b$. casei I90 had significantly higher levels of 3-methyl-1-butanol, 2-pentanol, and ethyl acetate than their respective control cheeses at the end of the ripening. These compounds are common constituents of the volatile profile of cheeses, contributing to the overall flavor. 3-Methyl 1-butanol is associated with fruity and alcohol notes at levels $>4.75 \mathrm{mg} /$ kg (Molimard and Spinnler, 1996).

In addition, acetic acid was significantly increased in experimental cheeses with $L$. casei I90, whereas levels determined by HPLC did not show significant differences. Differences are probably due to the extraction method: volatile compounds were extracted selectively from the headspace of the sample, whereas organic acids were analyzed in a water extract of cheeses.

Similar differing trends were observed for 3-methyl1-butanol, a branched-chain primary alcohol derived from catabolism of leucine, which was increased in experimental cheeses with $L b$. casei I90, whereas 3-methyl butanoic acid, also derived from leucine, was found at significantly higher concentration in control cheeses.

\section{Sensory Analysis}

Triangle aroma tests revealed highly significant differences $(P \leq 0.001)$ between the aroma of cheeses made with and without added lactobacilli, for both strains studied. According to the applied standard (AFNOR, 1995), the test was extended to investigate the character of the differences. In trial 1, 100\% of the panelists identified the different sample. All panelists commented that the aroma of the cheeses with $L b$. plantarum I91 was more buttery, lactic, and fresh compared with that of control cheeses. Regarding trial 2, 11 of the 12 members of the panel correctly identified the different sample, and commented that aroma of cheeses with $L b$. casei I90 was more buttery than that of control cheeses.

The results obtained indicated that both Lb. plantarum 191 and $L b$. casei 190 changed the sensory attributes of miniature Cremoso cheeses. On the other hand, comments of most panelists about the higher buttery aroma in experimental cheeses agree with the higher concentration of diacetyl and acetoin detected in the experimental cheeses. As discussed above, diacetyl and acetoin are associated with the soft, buttery, and pleasant aroma of Cheddar and short-ripened washed curd cheeses (Drake et al., 1999; Hynes et al., 2003b; Kieronczyk et al., 2004). In addition, higher levels of 3-methyl-1-butanol have been associated with a pleasant aroma of fresh cheese, and this compound was found at significantly higher concentration in experimental cheeses with Lb. casei I90 (Curioni and Bosset, 2002).

In in vitro assays, as well as in fermented milks, some strains of Lb. casei, Lb. plantarum, and Lactobacillus paracasei have demonstrated the ability to produce large amounts of diacetyl or acetoin, which resulted in an intensification of the buttery flavor note (Drake et al., 1999; Kieronczyk et al., 2004). Similar results were obtained by Thage et al. (2005) in a semi-hard cheese only for 1 of 3 strains of $L b$. paracasei tested. In contrast with these results, Skeie et al. (2008a) did not observe any influence on the sensory characteristics of adjunct-treated cheeses, despite detection of higher concentration of diacetyl and acetoin in those cheeses.

\section{CONCLUSIONS}

Cheeses with $L b$. plantarum I91 showed an increased content of FAA and changes in FAA profiles: 9 of 16 FAA analyzed had higher concentrations in cheeses containing this strain than in controls without lactobacilli. The influence of $L b$. case $i$ I90 was less evident as the total amount of FAA did not increase and only 5 of 16 FAA analyzed increased significantly. The amount of diacetyl, a key flavor compound that imparts a buttery note to soft cheeses, was significantly higher in cheeses with $L b$. plantarum I91 and $L b$. casei $\mathrm{I} 90$ than in control cheeses. Acetoin, which also has a buttery note but is much less powerful than diacetyl, also increased significantly in both types of experimental cheeses. The production of acetoin and diacetyl may derive from either citrate or aspartic acid catabolism. However, the improved production of acetoin and diacetyl was consistent with increased aspartate content in lactobacilliadded cheeses, whereas citrate was available at similar levels in control and experimental cheeses. In summary, the strains assayed were able to increase the availability of some of the precursors of aroma compounds and enhance their transformation. In addition, both adjunct lactobacilli generated changes in soft cheese aroma that the majority of panelists mentioned as positive. Additional cheesemaking experiments on the pilot-plant scale will be useful to verify the robustness of the technological properties of Lactobacillus plantarum I91 and Lactobacillus casei I90, and to provide enough amount of sample for a 12-member panel for descriptive sensory analysis. These types of experiments are generally needed to increase credibility for decision-makers in the dairy industry and will be performed in our institute.

\section{ACKNOWLEDGMENTS}

The authors acknowledge the financial support from Agencia Nacional de Promoción Científica y Tecnológi- 
ca and Universidad Nacional del Litoral (Proyecto PICTO-UNL 2003, 09-13227). Verónica Wolf recognizes CCT CONICET (Santa Fe, Argentina) and particularly Cristina Zalazar for the use of the GC-MS equipment.

\section{REFERENCES}

Abeijón Mukdsi, M. C., R. B. Medina, M. Alvarez, and S. N. González. 2009. Ester synthesis by lactic acid bacteria isolated from goat's and ewe's milk and cheeses. Food Chem. 117:241-247.

AFNOR. 1995. NFV 09-013: Contrôle de la qualité des produits alimentaires. Pages 201-208 in Analyse sensorielle; Méthodologie: Essai triangulaire. AFNOR, Paris, France.

Banks, J. M., and A. G. Williams. 2004. The role of nonstarter lactic acid bacteria in Cheddar cheese ripening. Int. J. Dairy Technol. $57: 145-152$.

Bergamini, C. V., E. Hynes, S. B. Palma, N. Sabbag, and C. A. Zalazar. 2009. Proteolytic activity of three probiotic strains in semihard cheese as single and mixed cultures: L. acidophilus, L. paracasei and B. lactis. Int. Dairy J. 19:467-475.

Bergamini, C. V., I. V. Wolf, M. C. Perotti, and C. A. Zalazar. 2010. Characterization of biochemical changes during ripening in $\mathrm{Ar}$ gentinean sheep cheeses. Small Rumin. Res. doi:10.1016/j.smallrumres.2010.07.004. In press.

Bintsis, T., and R. K. Robinson. 2004. A study of the effects of adjunct cultures on the aroma compounds of Feta-type cheese. Food Chem. 88:435-441.

Bradley, R. L., E. Arnold, D. M. Barbano, R. G. Semerad, D. E. Smith, and B. K. Vines. 1993. Chemical and physical methods. Pages 433-531 in Standard Methods for the Examination of Dairy Products. R. T. Marshall, ed. American Public Health Association, Washington, DC.

Briggiler-Marcó, M., M. L. Capra, A. Quiberoni, G. Vinderola, J. A. Reinheimer, and E. Hynes. 2007. Nonstarter Lactobacillus strains as adjunct cultures for cheese making: In vitro characterization and performance in two model cheeses. J. Dairy Sci. 90:4532-4542.

Bude-Ugarte, M., D. Guglielmotti, G. Giraffa, J. A. Reinheimer, and E. Hynes. 2006. Non-starter lactobacilli from Argentinean cheeses. J. Food Prot. 69:2983-2991.

Buffa, M., B. Guamis, J. Saldo, and A. Trujillo. 2004. Changes in organic acids during ripening of cheeses made from raw, pasteurised or high-pressure-treated goats' milk. Lebensm. Wiss. Technol. $37: 247-253$.

Christen, G. L., P. M. Davidson, J. S. McAllister, and L. A. Roth. 1993. Coliform and other indicator bacteria. Pages 247-269 in Standard Methods for the Examination of Dairy Products. R. T. Marshall, ed. American Public Health Association, Washington, DC.

Crow, V., B. Curry, and M. Hayes. 2001. The ecology of non-starter lactic acid bacteria (NSLAB) and their use as adjuncts in New Zealand Cheddar. Int. Dairy J. 11:275-283.

Curioni, P. M. G., and J. O. Bosset. 2002. Key odorants in various cheese types as determined by gas chromatography-olfactometry. Int. Dairy J. 12:959-984.

Díaz-Muñiz, I., D. S. Banavara, M. F. Budinich, S. A. Rankin, E. G. Dudley, and J. L. Steele. 2006. Lactobacillus casei metabolic potential to utilize citrate as an energy source in ripening cheese: A bioinformatics approach. J. Appl. Microbiol. 101:872-882.

Drake, M. A., Y. Karagül-Yüceer, X. Q. Chen, and K. R. Cadwallader. 1999. Characterization of desirable and undesirable lactobacilli from cheese in fermented milk. Lebensm. Wiss. Technol. 32:433-439.

Farkye, N. Y., S. A. Madkor, and H. G. Atkins. 1995. Proteolytic abilities of some lactic acid bacteria in a model cheese system. Int. Dairy J. 5:715-725.

Frank, J. F., G. L. Christen, and L. B. Bullerman. 1993. Tests for groups of microorganisms. Pages 271-286 in Standard Methods for the Examination of Dairy Products. R. T. Marshall, ed. American Public Health Association, Washington, DC.
Grappin, R., and E. Beuvier. 1997. Possible implications of milk pasteurization on the manufacture and sensory quality of ripened cheese. Int. Dairy J. 7:751-761.

Hynes, E., C. Bach, G. Lamberet, J. C. Ogier, O. Son, and A. Delacroix-Buchet. 2003b. Contribution of starter lactococci and adjunct lactobacilli to proteolysis, volatile profiles and sensory characteristics of washed-curd cheese. Lait 83:31-43.

Hynes, E., and C. V. Bergamini. 2006. Rol de las NSLAB (Non Starter Lactic Acid Bacteria) en la maduración de quesos. Pages 245-265 in Avances en Microbiología, Bioquímica y Tecnología de Quesos. J. A. Reinheimer and C. A. Zalazar, ed. Ediciones UNL, Santa Fe, Argentina.

Hynes, E., A. Delacroix-Buchet, C. Meinardi, and C. A. Zalazar. 1999 Relation between $\mathrm{pH}$, degree of proteolysis and consistency in soft cheese. Aust. J. Dairy Technol. 54:24-27.

Hynes, E., J. C. Ogier, and A. Delacroix-Buchet. 2003a. Influence of starter and adjunct lactobacilli culture on ripening of miniature washed-curd cheeses. Lait 83:17-29.

IDF. 1982. Standard Method 4A: Determination of the total solids content (cheese and processed cheese). Int. Dairy Fed., Brussels, Belgium.

IDF. 1993. Standard Method 20B: Milk: Determination of nitrogen content. Int. Dairy Fed., Brussels, Belgium.

IDF. 1997. Standard Method 152A: Milk and milk products. Determination of fat content (general guidance on the use of butyrometric methods). Int. Dairy Fed., Brussels, Belgium.

Izco, J. M., M. Tormo, and R. Jiménez-Flores. 2002. Rapid simultaneous determination of organic acids, free amino acids, and lactose in cheese by capillary electrophoresis. J. Dairy Sci. 85:2122-2129.

Kaminarides, S., P. Stamou, and T. Massouras. 2007. Changes of organic acids, volatile aroma compounds and sensory characteristics of Halloumi cheese kept in brine. Food Chem. 100:219-225

Kieronczyk, A., S. Skeie, T. Langsrud, D. Le Bars, and M. Yvon. 2004. The nature of the aroma compounds produced in a cheese model by glutamate dehydrogenase positive Lactobacillus INF15D depends on its relative aminotransferase activities towards the different amino acids. Int. Dairy J. 14:227-235.

Kocaoglu-Vurma, N. A., W. J. Harper, M. A. Drake, and P. D. Courtney. 2008. Microbiological, chemical, and sensory characteristics of Swiss cheese manufactured with adjunct Lactobacillus strains using a low cooking temperature. J. Dairy Sci. 91:2947-2959.

Kondyli, E., M. C. Katsiari, T. Masouras, and L. P. Voutsinas. 2002. Free fatty acids and volatile compounds of low-fat Feta-type cheese made with a commercial adjunct culture. Food Chem. 79:199205.

Le Bars, D., and M. Yvon. 2008. Formation of diacetyl and acetoin by Lactococcus lactis via aspartate catabolism. J. Appl. Microbiol. 104:171-177.

Le Quéré, J.-L., and P. Molimard. 2003. Cheese Flavor. Pages 330-340 in Encyclopedia of Dairy Sciences, Vol. 1. H. Roginsky, J. Fuquay, and P. Fox, ed. Academic Press, London, UK.

Liu, S.-Q., R. Holland, and V. L. Crow. 1998. Ethyl butanoate formation by dairy lactic acid bacteria. Int. Dairy J. 8:651-657.

Liu, S.-Q., R. Holland, and V. L. Crow. 2003. Ester synthesis in an aqueous environment by Streptococcus thermophilus and other dairy lactic acid bacteria. Appl. Microbiol. Biotechnol. 63:81-88.

Liu, S.-Q., R. Holland, and V. L. Crow. 2004. Esters and their biosynthesis in fermented dairy products: A review. Int. Dairy J. 14:923-945.

Lues, J. F. R. 2000. Organic acid and residual sugar variation in a South African cheddar cheese and possible relationships with uniformity. J. Food Compost. Anal. 13:819-825.

Macedo, A. C., M. Vieira, R. Poças, and F. X. Malcata. 2000. Peptide hydrolase system of lactic acid bacteria isolated from Serra da Estrela cheese. Int. Dairy J. 10:769-774.

Mangia, N. P., M. A. Murgia, G. Garau, M. G. Sanna, and P. Deiana. 2008. Influence of selected lab cultures on the evolution of free amino acids, free fatty acids and Fiore Sardo cheese microflora during the ripening. Food Microbiol. 25:366-377. 
Martley, F. G., and V. L. Crow. 1993. Interactions between non-starter microorganisms during cheese manufacture and ripening. Int. Dairy J. 3:461-483.

McSweeney, P. L. H., and M. J. Sousa. 2000. Biochemical pathways for the production of flavor compounds in cheese during ripening. Lait 80:293-324.

McSweeney, P. L. H., E. M. Walsh, P. F. Fox, T. M. Cogan, F. D. Drinan, and M. Castelo-Gonzalez. 1994. A procedure for the manufacture of Cheddar cheese under controlled bacteriological conditions and the effect of adjunct lactobacilli on cheese quality. Ir. J. Agric. Food Res. 33:183-192.

Milesi, M. M., M. Candioti, and E. Hynes. 2007. Mini soft cheese as a simple model for biochemical studies on cheesemaking and ripening. Lebensm. Wiss. Technol. 40:1427-1433.

Milesi, M. M., P. L. H. McSweeney, and E. R. Hynes. 2008. Viability and contribution to proteolysis of an adjunct culture of Lactobacillus plantarum in two model cheese systems: Cheddar cheese-type and soft-cheese type. J. Appl. Microbiol. 105:884-892.

Molimard, P., and H. E. Spinnler. 1996. Review: Compounds involved in the flavor of surface mold-ripened cheeses: Origins and properties. J. Dairy Sci. 79:169-184.

Morea, M., A. Matarante, R. Di Cagno, F. Baruzzi, and F. Minervini. 2007. Contribution of authochthonous non-starter lactobacilli to proteolysis in Caciocavallo Pugliese cheese. Int. Dairy J. 17:525534.

Oneca, M., M. Ortigosa, A. Irigoyen, and P. Torre. 2007. Proteolytic activity of some Lactobacillus paracasei strains in a model ovinemilk curd system: Determination of free amino acids by RP-HPLC. Food Chem. 100:1602-1610.

Ortigosa, M., C. Arizcun, A. Irigoyen, M. Oneca, and P. Torre. 2006. Effect of lactobacillus adjunct cultures on the microbiological and physicochemical characteristics of Roncal-type ewes'-milk cheese. Food Microbiol. 23:591-598.

Palles, T., T. Beresford, S. Condon, and T. M. Cogan. 1998. Citrate metabolism in Lactobacillus casei and Lactobacillus plantarum. J. Appl. Microbiol. 85:147-154.

Parra, L., T. Requena, V. Casal, and R. Gómez. 1996. Proteolytic activity of lactobacilli in a model goats' milk curd system. Lett. Appl. Microbiol. 23:375-378.

Peláez, C., and T. Requena. 2005. Exploiting the potential of bacteria in the cheese ecosystem. Int. Dairy J. 15:831-844.

Poveda, J. M., M. J. Sousa, L. Cabezas, and P. L. H. McSweeney. 2003. Preliminary observations on proteolysis in Manchego cheese made with a defined-strain starter culture and adjunct starter (Lactobacillus plantarum) or a commercial starter. Int. Dairy J. 13:169-178.
Preininger, M., and W. Grosch. 1994. Evaluation of key odorants of the neutral volatiles of Emmentaler cheese by the calculation of odour activity values. Lebensm. Wiss. Technol. 27:237-244.

Qian, M., and G. Reineccius. 2003. Static headspace and aroma extract dilution analysis of Parmigiano Reggiano cheese. J. Food Sci. 68:794-798.

Skeie, S., A. Kieronczyk, S. Eidet, M. Reitan, K. Olsen, and H. Østlie. 2008b. Interaction between starter bacteria and adjunct Lactobacillus plantarum INF15D on the degradation of citrate, asparagines and aspartate in a washed-curd cheese. Int. Dairy J. 18:169-177.

Skeie, S., A. Kieronczyk, R. M. Næssa, and H. Østlie. 2008a. Lactobacillus adjuncts in cheese: Their influence on the degradation of citrate and serine during ripening of a washed curd cheese. Int. Dairy J. 18:158-168.

Smit, G., B. A. Smit, and W. J. M. Engels. 2005. Flavor formation by lactic acid bacteria and biochemical flavor profiling of cheese products. FEMS Microbiol. Rev. 29:591-610.

Tanous, C., A. Kieronczyk, S. Helinck, E. Chambellon, and M. Yvon. 2002. Glutamate dehydrogenase activity: A major criterion for the selection of flavor-producing lactic acid bacteria strains. Antonie van Leeuwenhoek 82:271-278.

Tavaria, F. K., S. Dahl, F. J. Carbakkim, and F. X. Malcata. 2002. Amino acid catabolism and generation of volatiles by lactic acid bacteria. J. Dairy Sci. 85:2462-2470.

Tavaria, F. K., and F. X. Malcata. 2003. Enzymatic activities of nonstarter lactic acid bacteria isolated from a traditional Portuguese cheese. Enzyme Microb. Technol. 33:236-243.

Thage, B. V., M. L. Broe, M. H. Petersen, M. A. Petersen, M. Bennedsen, and Y. Ardö. 2005. Aroma development in semi-hard reducedfat cheese inoculated with Lactobacillus paracasei strains with different aminotransferase profiles. Int. Dairy J. 15:795-805.

Williams, A. G., S.-C. Choi, and J. M. Banks. 2002. Variability of the species and strain phenotype composition of the non-starter lactic acid bacterial population of Cheddar cheese manufactured in a commercial creamery. Food Res. Int. 35:483-493.

Wouters, J. T. M., E. H. E. Ayad, J. Hugenholtz, and G. Smit. 2002. Microbes from raw milk for fermented dairy products. Int. Dairy J. 12:91-109.

Yvon, M. 2006. Key enzymes for flavor formation by lactic acid bacteria. Aust. J. Dairy Technol. 61:16-24.

Zeppa, G., L. Conterno, and V. Gerbi. 2001. Determination of organic acids, sugars, diacetyl, and acetoin in cheese by high-performance liquid chromatography. J. Agric. Food Chem. 49:2722-2726. 